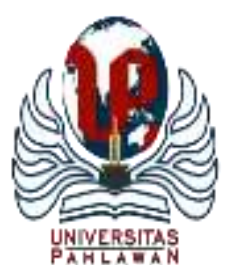

Edukatif : Jurnal Ilmu Pendidikan Volume 3 Nomor 6 Tahun 2021 Halm 4254 - 4262

EDUKATIF: JURNAL ILMU PENDIDIKAN

Research \& Learning in Education

https://edukatif.org/index.php/edukatif/index

\title{
Peran Media Sosial dalam Menunjang Pembelajaran Mata Kuliah Pendidikan Agama Islam dan Pembinaan Karakter Mahasiswa
}

\author{
Faqihatin $^{凶}$ \\ Universitas Qomaruddin Bungah Gresik, Indonesia \\ E-mail : faqihatin@uqgresik.ac.id
}

\begin{abstract}
Abstrak
Media sosial menjadi konsumsi sehari-hari hampir sebagian umat manusia di seluruh dunia. Hal yang paling menonjol dari generasi milenial adalah demikian gandrung dengan internet dan melek informasi. Kemajuan internet seakan menjadikan dunia tanpa batas dan di internet semua hal bisa ditemukan. Berbagai sumber informasi benar maupun salah begitu mudah didapatkan.Kemajuan ilmu pengetahuan di era milenial, terutama berkembangnya teknologi digital banyak memberikan manfaat positif, tetapi juga memberikan peluang yang besar terhadap dampak-dampak negatif kepada mahasiswa dan remaja umumnya. Pembelajaran mata kuliah Pendidikan agama Islam harus mengikuti zaman, yakni memanfaatkan media sosial yang mudah digunakan dan familiar dengan mahasiswa sehingga mereka merasa senang dan nyaman untuk belajar. Pendidikan agama Islam diharapkan dapat membentuk karakter bangsa terutama mahasiswa agar dapat memanfaatkan hal-hal positif yang diajarkan oleh agama Islam terutama akhlak dan moral yang baik. Pendidikan agama Islam diharapkan agar mahasiswa sebagai generasi milineal agar tidak diambil alih oleh media sosial yang frekuensinya lebih banyak daripada pembelajaran moral dan akhlak itu sendiri.
\end{abstract}

Kata kunci : media sosial, pendidikan agama Islam, pendidikan karakter

Abstract

Social media has become the daily consumption of almost all people around the world. The most prominent thing about the millennial generation is that they are so infatuated with the internet and are information literate. The progress of the internet seems to make the world without limits and on the internet all things can be found. Various sources of right and wrong information are so easy to find. The advancement of science in the millennial era, especially the development of digital technology has many positive benefits, but also provides great opportunities for negative impacts on students and adolescents in general. Learning Islamic religious education courses must follow the times, namely utilizing social media that is easy to use and familiar with students so that they feel happy and comfortable to learn. Islamic religious education is expected to shape the character of the nation, especially students so that they can take advantage of the positive things taught by Islam, especially good morals and morals. Islamic religious education is expected so that students as the millennial generation are not taken over by social media whose frequency is more than moral and moral learning itself.

Keywords: social media, Islamic religious education, character education

Copyright (c) 2021 Faqihatin

$\triangle$ Corresponding author:

Email : faqihatin@uqgresik.ac.id

DOI $\quad$ : https://doi.org/10.31004/edukatif.v3i6.865

ISSN 2656-8063 (Media Cetak)

ISSN 2656-8071 (Media Online)

Edukatif : Jurnal Ilmu Pendidikan Vol 3 No 6 Tahun 2021 p-ISSN 2656-8063 e-ISSN 2656-8071 
4255 Peran Media Sosial dalam Menunjang Pembelajaran Mata Kuliah Pendidikan Agama Islam dan Pembinaan Karakter Mahasiswa - Faqihatin

DOI: https://doi.org/10.31004/edukatif.v3i6.865

\section{PENDAHULUAN}

Di era milineal atau era kekinian banyak sorotan bahwa media sosial yang telah mengambil alih pembentukan karakter bangsa. Hal yang paling menonjol dari generasi milenial adalah demikian gandrung dengan internet dan melek informasi. Kemajuan internet seakan menjadikan dunia tanpa batas dan di internet semua hal bisa ditemukan. Berbagai sumber informasi benar maupun salah begitu mudah didapatkan. Hal ini membutuhkan kejelian dalam mengambil sumber informasi dari sumber yang benar-benar dapat dipertanggung jawabkan, jika terjadi kesalahan informasi akan berakibat fatal.

Perkembangan dan kemajuan teknologi informasi berdampak ganda. Dampak positif diantaranya memberikan kemudahan dalam komunikasi dan informasi, serta memberikan kemudahan dalam urusan ekonomi, sosial dan budaya. Akan tetapi dampak negatifnya juga besar dan tidak menutup kemungkinan berpotensi menyebabkan keretakan bangsa, terjadinya degradasi moral dan kejahatan-kejahatan dunia maya lainnya. Kondisi demikian amat mengkhawatirkan. Hal ini diperkuat dengan kecenderungan generasi muda yang menjadikan internet dan media sosial sebagai tempat mencari informasi. Tidak jarang, mereka menelan informasi tersebut mentah-mentah, tanpa melakukan klarifikasi terlebih dahulu. Bahwa media sosial telah menjadi gaya hidup dan membentuk pola pikir. Pola pikir akan membentuk keyakinan dan keyakinan akan membentuk perilaku. Perilaku yang terus diulang akan membentuk karakter. (Basarah, 2021)

Di sinilah peran pembinaan moral yang terus ditanamkan kepada anak didik terutama mahasiswa Program Studi Teknik Informatika Universitas Qomaruddin Gresik, terutama pada mata kuliah Pendidikan Agama Islam harus terus ditanamkan pembinaan moral dan akhlak sesuai dengan ajaran syariat Islam yang benar. Selain itu, peran keluarga dalam memberikan pendidikan keagamaan dan literasi digital juga penting karena keluargalah institusi utama tempat proses sosialisasi seseorang terbentuk.

Rumusan masalah penelitian ini adalah bagaimana Peran Media Sosial dalam Menunjang Pembelajaran Mata kuliah Pendidikan Agama Islam dan Pembinaan Karakter Mahasiswa Program Studi Teknik Informatika Universitas Qomaruddin Gresik?

\section{METODOLOGI}

Penelitian ini adalah mengkaji dari berbagai sumber literatur baik buku, artikel jurnal dan website untuk mendapatkan banyak masukan dan memberikan gambaran deskripsi terhadap perkembangan media sosial dan pengaruhnya dalam mendukung pembelajaran mata kuliah pendidikan agama Islam dan pembinaan karakter mahasiswa program studi teknik Informatika Universitas Qomaruddin Gresik.

\section{HASIL DAN PEMBAHASAN PENELITIAN}

\section{Pendidikan dan Pengajaran Agama Islam}

Pendidikan dapat diartikan sebagai bimbingan secara sadar oleh pendidik terhadap perkembangan jasmani dan rohani peserta didik menuju terbentuknya kepribadian yang utama. Pendidkan dipandang sebagai salah satu aspek yang memiliki peranan pokok dalam membentuk generasi muda agar memiliki kepribadian yang utama.Dalam Islam pada mulanya pendidikan Islam disebut dengan kata "ta'dib". Kata "Ta'dib"mengacu pada pengertian yang lebih tinggi, dan mencakup unsur-unsur pengetahuan ('ilm) pengajaran (ta'lim) dan pengasuhan yang baik (tarbiyah). Akhirnya dalam perkembangan kata ta'dib sebagai istilah pendidikan telah hilang peredarannya, dan tidak dikenal lagi, sehingga ahli pendidik Islam bertemu dengan istilah At Tarbiyah atau Tarbiyah, sehingga sering disebut Tarbiyah. (Arfah, 2018). Kaidah pendidikan termaktub dalam Al Qur'an QS Al Baqarah : 31) yang artinya :

Dan Dia mengajarkan kepada Adam nama-nama (benda-benda) seluruhnya, kemudian mengemukakannya kepada para Malaikat lalu berfirman: "Sebutkanlah kepada-Ku nama benda-benda itu jika kamu mamang benar orangorang yang benar. (QS. Al-Baqarah:31) 
4256 Peran Media Sosial dalam Menunjang Pembelajaran Mata Kuliah Pendidikan Agama Islam dan Pembinaan Karakter Mahasiswa - Faqihatin

DOI: https://doi.org/10.31004/edukatif.v3i6.865

Agama islam ialah suatu suprasistem yang mengandung:

a. Sistem akidah atau keimanan dan keyakinan

b. Sistem syari'at, yaitu system nilai dan norma yang mengandung ketentuan perundang-undangan, peraturan, bimbingan, ajaran dan informasi.

c. Akhlak atau pola prilaku yang didasrkan pada suatu system nilai dan norma agama islam serta proses pembentukan ide atau konsep berpikir yang dapat melahirkan bentuk-bentuk pola kegiatan, interaksidan bentuk-bentuk institusi sosial tertentu maupun karya budaya yang bersifat material dan konseptual.(Muslimah, 2020)

Ajaran Islam ialah suatu proses penyampaian informasi yang kemudian diserap oleh masing-masing pribadi, sehingga menjiwai cara berfikir, bersikap, dan bertindak baik untuk dirinya sendiri maupun hubungannya dengan Allah dan hubungannya dengan manusia lain dan alam semesta.

Ajaran islam tidak memisahkan antara iman dan amal saleh. Oleh karena itu pengajaran islam adalah pendidikan iman dan pendidikan amal. Ajaran Islam berisi tentang sikap dan tingkah laku pribadi masyarakat, menuju kesejahteraan hidup individu dan masyarakat.(Ismail, 2018)

\section{Perkembangan Media Sosial}

Media sosial adalah saluran atau sarana pergaulan sosial secara online di dunia maya. Para pengguna media sosial berkomunikasi dan berinteraksi, saling kirim pesan, saling berbagi dan membangun jaringan. media sosial adalah media online yang mendukung interaksi sosial dan media sosial menggunakan teknologi berbasis web yang mengubah komunikasi menjadi dialog interaktif.

Dalam pemanfaatan media sosial memiliki pengaruh positif dan juga negatif yaitu :

a. Pengaruh Positif Media Sosial antara lain :

1) Mahasiswa dapat bersosialisasi dengan publik dan mengelola jaringan pertemanan. Mereka akan mampu bersosialisasi dengan masyarakat umum lainnya.

2) Mahasiswa akan termotivasi untuk belajar mengembangkan diri melalui teman-teman yang mereka jumpai secara online, karena mereka berinteraksi dan menerima umpan balik satu sama lain.

3) Mahasiswa mendapatkan ilmu dan informasi dengan mudah di segala bidang dari berbagai sumber perpustakaan dunia atau dari berbagai website. (Fathul Amin, 2019; Itiarani, 2019; Kaliky, 2016; Rahman, 2010)

b. Pengaruh Negatif media sosial antara lain :

1) Anak anak yang menggunakan jejaring sosial lebih banyak menghabiskan waktunya untuk bermain di dunia maya daripada dunia nyata.

2) Lupa waktu kalau sudah bermain jejaring sosial atau lebih tepatnya mengurangi waktu efektifnya

3) Tugas kuliah terbengkalai karena mereka lebih senang dan fokus bermain jejaring sosia dan menimbulkan penyakit malas dan lalai.

4) Bagi remaja, tidak ada aturan ejaan dan tata bahasa di situs jejaring sosial. Ini yang membuat mereka semakin sulit untuk membedakan antara berkomunikasi di situs jejaring sosial dan di dunia nyata.

5) Banyaknya tindakan kejahatan yang ditimbulkan dari jejaring sosial seperti penculikan, dan tindakan kriminal lainnya

6) Menganggu kesehatan(Zazin \& Zaim, 2019)

\section{Pembelajaran Pendidikan Agama Islam di zaman Milenial}

Di zaman era milineal 4.0, khususnya dunia pendidikan agama Islam, proses belajar dan mengajar agama islam telah berada dunia digital yang serba maju. Dalam kaitan ini, keberadaan dan peran media pembelajaran menjadi amat penting agar semakin efektif dan efesien proses pembelajaran. Karena kita semua 
4257 Peran Media Sosial dalam Menunjang Pembelajaran Mata Kuliah Pendidikan Agama Islam dan Pembinaan Karakter Mahasiswa - Faqihatin

DOI: https://doi.org/10.31004/edukatif.v3i6.865

akan hidup di dunia digital, tentu di dalam dunia pendidikan khususnya, persoalan kita tidak hanya materi yang dikuatkan, tapi juga medianya.(Ahmadi, 2018)

Karena media yang akan memudahkan tenaga pengajar dalam menghidupkan sumber literasi belajar dari digital. Sumber dan literasi belajar digital bukan sekadar mata pelajaran tentang komputer dan umum. Tetapi harus semua mata pelajaran lebih khusus pendidikan agama Islam yang perlu juga menggunakan teknologi 4.0 dalam keseharian mahasiswa. Anak zaman milenial tidak lagi membaca buku cetak, mereka menggunakan digital seperti halnya menghirup oksigen. Yang perlu diperhatikan adalah jangan salah memanfaatkan dengan pengadaan fasilitas yang semakin canggih saat ini. Terpenting adalah mengarahkan mereka untuk belajar secara proporsional dengan memberikan tugas-tugas terstruktur dan sistematis.(Romlah, n.d.)(Hidayat, 2011; Maesaroh, 2014; Miftah, n.d.; Ulfatin, 2015)

Menurut Fisk, sebagaimana telah dikemukakan oleh Anealka Aziz Hussin, terdapat sembilan tren terkait dengan Education 4.0. (a) Pertama, belajar dapat dilakukan kapan saja di mana saja. (b) Kedua, belajar akan bersifat perseorangan untuk masing-masing siswa. (c) Ketiga, siswa memiliki pilihan dalam menentukan bagaimana mereka ingin belajar.(d) Keempat, siswa akan dihadapkan pada pembelajaran berbasis proyek yang lebih banyak. (e) Kelima, siswa akan dihadapkan pada pembelajaran langsung melalui pengalaman lapangan seperti magang, proyek mentoring dan proyek kolaborasi. (f) Keenam, siswa akan terpapar dengan interpretasi data di mana mereka diminta untuk menerapkan pengetahuan teoritis mereka ke dalam angka dan menggunakan keterampilan penalaran mereka untuk membuat kesimpulan berdasarkan logika serta tren dari set data yang diberikan. ( $g$ ) Ketujuh, siswa akan dinilai secara berbeda dan platform konvensional untuk menilai siswa dapat menjadi tidak relevan atau tidak memadai. Pengetahuan faktual siswa dapat dinilai selama proses

pembelajara, sementara aplikasi pengetahuan dapat diuji ketika mereka mengerjakan proyek mereka di lapangan. (h)Kedelapan, pendapat siswa akan dipertimbangkan dalam merancang dan memperbarui kurikulum. (i) mahasiswa akan menjadi lebih mandiri dalam pembelajaran mereka sendiri, sehingga memaksa para guru untuk mengambil peran baru sebagai fasilitator yang akan memandu siswa melalui proses belajar mereka.(Zazin \& Zaim, 2019)

Media sosial yang ada tidak semua dapat digunakan sebagai media pembelajaran, facebook, youtube, google classroom, google meet, zoom, dan lain sebagainya adalah beberapa pilihan media sosial yang dapat digunakan sebagai alat pembelajaran. Media library online, elearning dan media pembelajaran daring yang dikembangkan oleh kemenag maupun kemendikbud dapat digunakan sebagai pendukung media pembelajaran. (Ani Jailani, Chaerul Rochman, 2019; Fathul Amin, 2019; Muslimah, 2020; Yulianti, 2013)

\section{Pembinaan Karakter Melalui Pendidikan Agama Islam}

Evaluasi dari Keberhasilan pendidikan karakter tidak dapat dinilai dengan tes formatif atau sumatif yang dinyatakan dalam skor. Tetapi tolak ukur dari keberhasilan pendidikan karakter adalah terbentuknya peserta didik yang berkarakter; berakhlak, berbudaya, santun, religius, kreatif, inovatif yang teraplikasi dalam kehidupan di sepanjang hayatnya. Oleh karena itu tentu tidak ada alat evaluasi yang tepat dan serta merta dapat menunjukkan keberhasilan pendidikan karakter (Ainiyah, 2013).

Adapun hal-hal yang perlu dibiasakan sebagai akhlak yang terpuji dalam Islam, antara lain:

a. Berani dalam kebaikan, berkata benar serta menciptakan manfaat, baik bagi diri maupun orang lain

b. Adil dalam memutuskan hokum tanpa membedakan kedudukan, status sosial ekonomi, maupun kekerabatan.

c. Arif dan bijaksana dalam mengambil keputusan

d. Pemurah dan suka menafkahkan rizki baik ketika lapang maupun sempit

e. Ikhlas dalam beramal semata-mata demi meraih rida Allah

f. Cepat bertobat kepada Allah ketika berdosa

g. Jujur dan amanah 
4258 Peran Media Sosial dalam Menunjang Pembelajaran Mata Kuliah Pendidikan Agama Islam dan Pembinaan Karakter Mahasiswa - Faqihatin

DOI: https://doi.org/10.31004/edukatif.v3i6.865

h. Tidak berkeluh kesah dalam menghadapi masalah hidup

i. Penuh kasih sayang

j. Lapang hati dan tidak balas dendam

k. Menjaga diri dari perbuatan yang menghancurkan kehormatan dan kesucian diri

1. Malu melakukan perbuatan yang tidak baik

m. Rela berkurban untuk kepentingan umat dan dalam membela agama Allah (Muslimah, 2020; Rahman, 2010; Utami, 2020; Windari, 2020; Yulianti, 2013)

Adapun ruang lingkup akhlak dalam Islam ada tiga, yakni mencakup akhlak manusia dengan Allah Swt., akhlak manusia dengan sesama manusia, dan akhlak manusia dengan makhluk lain. Di antara tiga cakupan akhlak tersebut, maka akhlak dengan Allah Swt. merupakan akhlak yang paling pokok dan ukuran bagi yang lain. Akhlak dengan Allah mencakup segala ketaatan kepada-Nya, yakni taat menjalankan segala perintah-Nya dan meninggalkan segala laranga-Nya. Jika akhlak dengan Allah SWT. baik, pasti akhlak dengan sesama manusia dan dengan makhluk lainnya akan baik pula. Jika seseorang akhlaknya dengan orang lain dan dengan alam lingkungannya tidak baik, maka akhlaknya dengan Allah Swt. sudah pasti belum baik. Adapun akhlak manusia kepada Allah Swt. antara lain ialah:

1) Beriman kepada Allah."Maka itu berimanlah kepada Allah dan Rasul-rasulNya; dan jika kamu beriman dan bertakwa, maka bagimu pahala yang besar."(QS Ali Imran [3]:179)

2) Beribadah kepada-Nya dan tidak menyekutukan-Nya. "Sembahlah Allah dan janganlah kamu mempersekutukan-Nya dengan sesuatu pun..."(QS. Al-Nisaa $\{4\}: 36)$ "Dan taatilah Allah dan Rasul, supaya kamu diberi rahmat."(QS Ali Imran [3]: 132)

3) Ikhlas. "Padahal mereka tidak disuruh kecuali supaya menyembah Allah dengan memurnikan ketaatan kepada-Nya dalam (menjalankan) agama yang lurus, dan supaya mereka mendirikan shalat dan menunaikan zakat; dan yang demikian itulah agama yang lurus.”(QS Al-Bayyinah [98]: 5)

4) Bersyukur atas segala karunia-Nya dan Qana'ah. "Hai orang-orang yang beriman, makanlah di antara rezeki yang baik-baik yang kami berikan kepadamu dan bersyukurlah kepada Allah, jika benar-benar kepada-Nya kamu menyembah.”(QS Al-Baqarah [2]: 55)

5) Tadharru' "Berdoalah kepada Tuhanmu dengan berendah diri dan suara yang lembut. Sesungguhnya Allah tidak menyukai orang-orang yang melampaui batas."(QS Al-A’raaf [7]: 55)

6) Doa dan berharap hanya kepada Allah. "Dan janganlah kamu membuat kerusakan di muka bumi, sesudah (Allah) memperbaikinya dan berdoalah kepada-Nya dengan rasa takut (tidak akan diterima) dan harapan (akan dikabulkan). Sesungguhnya rahmat Allah amat dekat kepada orang-orang yang berbuat baik.”(QS Al-A'raaf [7]: 56)

7) Sabar dan tidak mengenal putus asa. "Dan berapa banyaknya Nabi yang berperang bersama-sama mereka sejumlah besar dari pengikut (nya) yang bertakwa. Mereka tidak menjadi lemah karena bencana yang menimpa mereka di jalan Allah, dan tidak lesu dan tidak (pula) menyerah (kepada musuh). Allah menyukai orang-orang yang sabar."(QS. Ali Imran [3]: 146)

8) Menerima taqdir Allah."Maka barang siapa yang tidak beriman kepada qadar baik dan qadar buruk, Allah pasti akan membakarnya dengan api neraka."(HR Ibnu Wahab).

9) Husnuzh-zhan."janganlah mati salah seorang dari kalian kecuali dalam keadaan bersangka baik kepada Allah.'HR Muslim)

10) Tawakkal. "Maka apabila kamu telah membulatkan tekad, maka bertawakkallah kepada Allah. Sesungguhnya Allah menyukai orang-orang yang bertawakkal kepada-Nya."(QS Ali Imran [3]: 159

11) Malu kepada Allah.”Malu itu sebagian dari iman."(HR Muslim)

12) Taubat dan istighfar. "Hai orang-orang yang beriman, bertaubatlah kepada Allah dengan taubatan nasuhaa (taubat yang semurni-murninya). Mudah-mudahan Rabbmu akan menutupi kesalahan-kesalahanmu dan 
4259 Peran Media Sosial dalam Menunjang Pembelajaran Mata Kuliah Pendidikan Agama Islam dan Pembinaan Karakter Mahasiswa - Faqihatin

DOI: https://doi.org/10.31004/edukatif.v3i6.865

memasukkanmu ke dalam Jannah yang mengalir di bawahnya sungai-sungai."(QS At-Tahriim [66]: 8)(Fathul Amin, 2019)

Adapun akhlak terhadap sesama manusia antara lain adalah sebagai berikut:

1) Akhlak terhadap diri sendiri. Menjaga kesucian diri, baik kesucian batin maupun lahir. Suci batin adalah bersih dari segala bentuk keyakinan yang musyrik, dari penyakit dengki, buruk sangka dan penyakit hati lain. Bersih lahir ialah suci dari hadas kecil dan besar. ".....di dalamnya masjid itu ada orang-orang yang ingin membersihkan diri dan sesungguhnya Allah menyukai orang-orang yang bersih.” (QS Al-Taubah [9]: 108)

2) Memelihara kerapihan. Nabi Saw. Bersabda: "Sesungguhnya Allah itu indah dan menyukai keindahan."(HR Muslim)

3) Berlaku tenang dan istiqamah."Dan hamba-hamba Tuhan yang Maha Penyanyang itu (ialah) orang-orang yang berjalan di atas bumi dengan rendah hati dan apabila orang-orang Jahil menyapa mereka, mereka mengucapkan kata-kata (yang mengandung) keselamatan. (QS Al Furqan [25] ayat 63). Dan pada ayat lain disebutkan "sesungguhnya orang-orang yang mengatakan: "Tuhan Kami ialah Allah" kemudian mereka meneguhkan pendirian mereka, Maka malaikat akan turun kepada mereka dengan mengatakan: "Janganlah kamu takut dan janganlah merasa sedih; dan gembirakanlah mereka dengan Jannah yang telaorangh dijanjikan Allah kepadamu". (QS Fushilat [41] ayat 30)

4) Disiplin, yakni pandai menggunakan waktu sebaik mungkin. "Demi masa. Sesungguhnya manusia itu benar-benar dalam kerugian, kecuali orang-orang yang beriman dan mengerjakan amal saleh dan nasehat menasehati supaya mentaati kebenaran dan nasehat menasehati supaya menetapi kesabaran (QS Al Ashr [103] ayat 1-3).

5) Selalu menambah pengetahuan"Allah akan meninggikan orang-orang yang beriman di antaramu dan orang-orang yang diberi ilmu pengetahuan beberapa derajat, dan Allah maha mengetahui apa yang kamu kerjakan. "(QS Al Mujadilah [58] ayat 1)

6) Tidak melemparkan dirinya kedalam kehancuran, seperti minum khomer, narkoba, dan lain-lain. “... dan janganlah kamu menjatuhkan dirimu sendiri ke dalam kebinasaan, dan berbuat baiklah, karena Sesungguhnya Allah menyukai orang-orang yang berbuar baik. "QS Al-Baqarah [2] ayat 195). (Nuris, 2018)

Adapun akhlak terhadap keluarga antara lain adalah sebagai berikut :

1) Berlaku baik kepada keluarga. "Orang mu'min yang paling sempurna imannya adalah yang terbaik akhlaknya. Dan sebaik-baik diantara kamu ialah yang paling baik kepada istrinya." (HR Turmuzi).

2) Menunaikan hak dan kewajiban dalam keluarga. "Seorang suami adalah bertanggung jawab kepada keluarganya, dia kelak akan dituntut atas tanggung jawabnya tersebut, seorang istri adalah bertanggung jawab di rumah suaminya, dia juga kelak akan dituntut atas tanggung jawabnya tersebut. '(HR Bukhari dan Muslim)

3) Mengasuh dan mendidik anak. "Kewajiban orang tua kepada anaknya ialah memberikan nama yang baik, mengajarkan menulis dan menikahkan apabila telah dewasa. "(HR Ibnu Najjar)

4) Berbakti kepada kedua orang tua. "Dan Tuhanmu telah memerintahkan supaya kamu jangan menyembah selain Dia dan hendaklah kamu berbuat baik pada ibu bapakmu dengan sebaik-baiknya. Jika salah seorang diantaranya atau kedua-duanya sampai berumur lanjut dalam pemeliharaanmu, Maka sekali-sekali janganlah kamu mengatakan kepada keduanya perkataan "ah" dan janganlah kamu membentak mereka dan ucapkanlah kepada mereka perkataan yang mulia. "(QS.Al-Israa [17] ayat 23). Mengucapkan kata "Ah" kepada orangtua tidak dibolehkan oleh agama apalagi mengucapkan kata-kata atau memperlakukan mereka dengan lebih kasar daripada itu. Rasulullah SAW bersabda: "Semua dosa dilambatkan Allah membalasnya menurut apa yang dikehendaki-Nya sampai hari kiamat, kecuali kedurhakaan kepada 
4260 Peran Media Sosial dalam Menunjang Pembelajaran Mata Kuliah Pendidikan Agama Islam dan Pembinaan Karakter Mahasiswa - Faqihatin

DOI: https://doi.org/10.31004/edukatif.v3i6.865

orangtua, maka sesungguhnya Allah mempercepat pembalasannya di waktu dia masih hidup sebelum mati." (HR Thabrani)

5) Membangun silaturahin, baik kepada keluarga, tetangga maupun kepada masyarakat luas. Firman Allah “... dan bertakwalah kepada Allah yang dengan (mempergunakan) nama Nya kamu saling meminta satu sama lain, dan peliharalah hubungan silaturahim. Sesungguhnya Allah selalu menjaga dan mengawasi kamu." (QS Al-Nisaa [4]:1)(Fathul Amin, 2019)

Adapun akhlak terhadap tetangga dan masyarakat luas antara lain adalah sebagai berikut:

1) Berlaku baik terhadap tetangga. "Barangsiapa yang mengaku beriman kepada Allah dan hari akhir, maka berbuat baiklah kepada tetangganya." (HR Bukhari dan Muslim)

2) Memberikan apa yang menjadi hak tetangga. Sabda Nabi Saw: "'Hak tetangga yaitu: (1) Kalau ia ingin meminjam, hendaklah engkau pinjami. (2) Kalau ia minta tolong hendaklah engkau tolong. (3) Kalau ia sakit hendaklah engkau jenguk dia. (4) Kalau ia ada keperluan, hendaklah engkau beri kepadanya. (5) Kalau ia jatuh miskin, hendaklah engkau beri bantuan kepadanya. (6) Kalau ia mendapat kesenangan, hendaklah engkau ucapkan selamat kepadanya. (7) Kalau ia ditimpa kesusahan, hendaklah engkau hibur dia. (8) Kalau ia meninggal dunia, hendaklah engkau antarkan jenazahnya. (9) Jangan engkau membangun rumah lebih tinggi dari rumahnya kecuali engkau meminta izin kepadanya, karena hal itu menghalangi ia dari angina. (10) Jangan engkau ganggu ia dengan bau masakanmu kecuali engkau beri masakan itu. (11) Jika engkau membeli buah-buahan hendaklah engkau hadiahkan juga kepadanya, dan kalua engkau tidak memberi, bawalah masuk kedalam rumahmu secara sembunyi-sembunyi. (12) Dan jangan sampai anakmu keluar membawa buah-buahan itu, karena nanti anak(tetangga)nya sedih karena menginginkan buah itu."(HR Abu Syaikh).

3) Memberi hadiah. Nabi Saw. bersabda: "Jika engkau memasak gulai, maka banyakkanlah kuahnya serta perhatikanlah tetanggamu, kemudian hadiahkanlah sebagian daripadanya kepada tetanggamu, dengan cara yang baik." (HR Muslim).

4) Berbuat baik kepada semua orang. "Sembahlah Allah dan janganlah kamu mempersekutukan-Nya dengan sesuatupun., Dan berbuat baiklah kepada ibubapak, karib kerabat, anak-anak yatim, orang-orang miskin, tetangga yang dekat dan tetangga yang jauh, dan teman sejawat, Ibnu sabil dan hamba sahayamu. Sesungguhnya Allah tidak menyukai orang-orang yang sombong dan membanggabanggakan diri,’'(QS AlNisaa [4]: 36)

5) Menghormati guru. Sabda Nabi Saw. :'Muliakanlah 'ulama, karena mereka adalah pewaris para nabi; maka barang siapa memuliakan mereka, sesungguhnya mereka telah memuliakan Allah dan RasulNya.”(HR Thabrani).(Ibtisam Binti Nasar, 2020)

Pendidikan agama Islam bagi anak didik dirasakan sangat penting dalam membentuk dan mengembangkan karakter siswa. Pendidikan agama dan moral harus saling berintegrasi dan berinteraksi melalui realitas sosial yang berkembang di masyarakat. Pendidikan diyakini orang sebagai proses pembentukan pribadi manusia semenjak kecil sampai tua yang mengandung keyakinan bahwa Pendidikan menjadi proses yang tidak pernah selesai. Sebab dalam kenyataannya, Pendidikan yang memuat nilai-nilai keagamaan pada akhirnya mampu membentuk manusia seutuhnya.

\section{KESIMPULAN}

Kemajuan ilmu pengetahuan di era milenial, terutama berkembangnya teknologi digital banyak memberikan manfaat positif, tetapi juga memberikan peluang yang besar terhadap dampak-dampak negatif kepada mahasiswa dan remaja umumnya. Pembelajaran mata kuliah Pendidikan agama Islam harus mengikuti zaman, yakni memanfaatkan media sosial yang mudah digunakan dan familiar dengan mahasiswa sehingga mereka merasa senang dan nyaman untuk belajar. Pendidikan agama Islam diharapkan dapat 
4261 Peran Media Sosial dalam Menunjang Pembelajaran Mata Kuliah Pendidikan Agama Islam dan Pembinaan Karakter Mahasiswa - Faqihatin

DOI: https://doi.org/10.31004/edukatif.v3i6.865

membentuk karakter bangsa terutama mahasiswa agar dapat memanfaatkan hal-hal positif yang diajarkan oleh agama Islam terutama akhlak dan moral yang baik. Pendidikan agama Islam diharapkan agar mahasiswa sebagai generasi milineal agar tidak diambil alih oleh media sosial yang frekuensinya lebih banyak daripada pembelajaran moral dan akhlak itu sendiri.

\section{DAFTAR PUSTAKA}

Ahmadi. (2018). Eksistensi media sosial dalam meningkatkan motivasi belajar santri. Al Fikrah, 1(1), 46-55.

Ani Jailani, Chaerul Rochman, N. N. (2019). Peran Pendidikan Agama Islam dalam Membentuk Karakter Jujur Pada Siswa Ani Jailani 1, Chaerul Rochman 2, dan Nina Nurmila 3. Al Tadzkiyyah, Jurnal Pendidikan Agama Islam, 10(2), 257-264.

Arfah, N. (2018). Strategi Guru Pendidikan Agama Islam dalam Pemanfaatan Media Sosial sebagai Sarana Belajar Siswa pada Madrasah Tsanawiyah Swasta Al Washliyah Kolam. Fakultas Ilmu Tarbiyah dan Kegurua, Universitas Islam Negeri Sumatera Utara Medan.

Basarah, A. (2021). Media Sosial Alih Pembentukan Karakter Bangsa. Retrieved from https://www.tribunnews.com/kilas-kementerian/2019/09/08/basarah-media-sosial-ambil-alihpembentukan-karakter-bangsa.

Fathul Amin. (2019). Pembentukan Karakter Melalui Pendidikan Agama Islam. Tadris: Jurnal Penelitian Dan Pemikiran Pendidikan Islam, 12(2), 33-45. https://doi.org/10.51675/jt.v12i2.22

Hidayat, S. (2011). Penggunaan Media Pembelajaran Dalam Mata Pelajaran Pendidikan Agama Islam.

Ibtisam Binti Nasar, J. U. (2020). Strategi Guru Pendidikan Agama Islam dalam Memanfaatkan Media Sosial Sebagai Sarana Belajar Siswa di SMA Negeri 4 Pasuruan. Al Makrifat, 5(2), 180-197.

Ismail. (2018). Peran Guru Pendidikan Agama Islam Dalam Mengantisipasi Dampak Penggunaan Media Sosial Bagi Siswa Sekolah Menengah Pertama. 1(1), 105-120.

Itiarani. (2019). Penggunaan Video dari Youtube sebagai Media dalam Pembelajaran Pendidikan Agama Islam di Kelas VIII SMP Negeri 20 Bandar Lampung (Vol. 11). Retrieved from

http://scioteca.caf.com/bitstream/handle/123456789/1091/RED2017-Eng-

8ene.pdf?sequence=12\&isAllowed=y\%0Ahttp://dx.doi.org/10.1016/j.regsciurbeco.2008.06.005\%0Ahtt ps://www.researchgate.net/publication/305320484_sistem_pembetungan_terpusat_strategi_melestari

Kaliky, M. (2016). Penggunaan Media Pembelajaran dalam Meningkatkan Mutu Pendidikan Agama Islam di SMAN 13 Ambon.

Maesaroh, S. (2014). Penggunaan Media Pembelajaran Pendidikan Agama Islam di SD Muhammadiyah Bancarkembar Kecamatan Purwokerto Utara Skripsi Program Studi Pendidikan Agama Islam (Transfer) Jurusan Tarbiyah Sekolah Tinggi Agama Islam Negeri.

Miftah, M. (n.d.). Fungsi dan Peran Media Pembelajaran Sebagai Upaya Peningkatan Kemampuan Belajar Siswa. 95-105.

Muslimah. (2020). Peran Media Sosial dalam Pendidikan dan Pengajaran Agama Islam pada Masa Pandemi Covid 19. 10(Juni), 40-59.

Nuris, M. (2018). Penggunaan Media Berbasis Teknologi dan Komunikasi dalam Pembelajaran Pendidikan Agama Islam. Retrieved from

http://journal.stainkudus.ac.id/index.php/equilibrium/article/view/1268/1127\%0Ahttp://publicacoes.card iol.br/portal/ijcs/portugues/2018/v3103/pdf/3103009.pdf\%0Ahttp://www.scielo.org.co/scielo.php?script =sci_arttext\&pid=S0121-75772018000200067\&lng=en\&tlng=

Rahman, G. (2010). Pemanfaatan Media Pembelajaran Dalam Mengefektifkan Pembelajaran Pendidikan Agama Islam di SMA Negeri I Polewali (Vol. 7). Retrieved from

http://dx.doi.org/10.1016/j.tplants.2011.03.004\%0Ahttp://dx.doi.org/10.1016/j.pbi.2010.01.004\%0Ahttp

Edukatif : Jurnal Ilmu Pendidikan Vol 3 No 6 Tahun 2021 p-ISSN 2656-8063 e-ISSN 2656-8071 
4262 Peran Media Sosial dalam Menunjang Pembelajaran Mata Kuliah Pendidikan Agama Islam dan Pembinaan Karakter Mahasiswa - Faqihatin

DOI: https://doi.org/10.31004/edukatif.v3i6.865

://www.biomedcentral.com/1471-

2156/12/42\%0Ahttp://dx.doi.org/10.1016/j.biotechadv.2009.11.005\%0Ahttp://www.sciencemag.org/co ntent/323/5911/240.short\%0Apape

Romlah, S. (n.d.). Pemanfaatan Media Pembelajaran dalam Pendidikan Agama Islam Abstrak.

Ulfatin, N. (2015). Pengaruh Pemanfaatan Media SOsial Facebook dalam Meningkatkan Motivasi dan Hasil Belajar Pendidikan Agama Islam siswa Kelas VIII di SMP Negeri Sindue Donggala. 1-27.

Utami, M. P. (2020). Pengaruh Penggunaan Media Sosial terhadap Akhlak Siswa di MTS Tarbiyah Islamiyah Kerkap.

Windari, R. (2020). Pengaruh Penggunaan Media Sosial Terhadap Pemahaman Keislaman Mahasiswa PAI di IAIN Purwokerto.

Yulianti, V. (2013). ( Studi Kasus Kelas X di Laboratorium Agama MAN Parakan Temanggung Tahun Pelajaran 2012 / 2013 ).

Zazin, N., \& Zaim, M. (2019). Media Pembelajaran Agama Islam Berbasis Media Sosial pada Generasi-Z. Proceeding Antasari International Conference. 